\title{
Comparison of oral prednisolone and intramuscular depot triamcinolone in patients with severe chronic asthma
}

\author{
RICHARD F WILLEY, RONALD J FERGUSSON, DAVID J GODDEN, \\ GRAHAM K CROMPTON, IAN WB GRANT
}

From the Respiratory Unit, Northern General Hospital, Edinburgh

\begin{abstract}
In a double blind crossover study oral prednisolone was compared with intramuscular depot triamcinolone in the treatment of 20 patients with severe chronic asthma. A short term study comparing each treatment over four weeks showed only minor differences in therapeutic efficacy, but at the end of 24 week periods on each of the two treatments triamcinolone was significantly more effective than prednisolone in terms of forced expiratory volume in one second and forced vital capacity. Better control of asthma was accompanied by a significant fall in weight and some evidence of reduced adrenal suppression (improved cortisol response following a short tetracosactrin test). Side effects, including menstrual irregularities, muscle pain, and hirsuitism, were, however, more common during treatment with triamcinolone.
\end{abstract}

Although treatment with corticosteroids by inhalation controls symptoms in many patients with chronic asthma, those with either severe asthma or a poor response to inhaled corticosteroid aerosols often require supplementary systemic treatment. Traditionally this is given in the form of oral prednisolone. A maintenance dose of $10 \mathrm{mg}$ or more a day is required in only a small proportion of patients with chronic asthma, but such patients form a significant number of those attending asthma clinics and they are prone to develop side effects that may be seriously disabling and occasionally life threatening.

It has been suggested in an open study' that better control is achieved, with no greater incidence of side effects, when corticosteroid treatment is given in the form of injections of depot triamcinolone at intervals of four weeks. This paper describes the results of studies designed to compare treatment with oral prednisolone and intramuscular triamcinolone in patients with poorly controlled asthma. A double blind crossover study of four weeks of each treatment was undertaken first, but as it showed only

Address for reprint requests: Dr RF Willey, Royal Lancaster Infirmary, Lancaster LA1 4RP.

Accepted 4 January 1984 minor differences in therapeutic efficacy it was followed by a study of the same design in which each treatment was continued for 24 weeks.

\section{Patients and methods}

Twenty outpatients ( 8 male and 12 female) with chronic bronchial asthma were included in the study. Their ages ranged from 15 to 76 years (mean 48.9). Informed consent for inclusion in the study was obtained in all cases.

All the patients had previously shown an improvement in $\mathrm{FEV}_{1}$ of at least $25 \%$ after treatment with an aqueous salbutamol aerosol $(5 \mathrm{mg})$ delivered by intermittent positive pressure breathing (IPPB). They all had an FEV 1 of less than $75 \%$ of the predicted normal despite regular treatment with oral prednisolone, $10 \mathrm{mg}$ daily, and inhaled beclomethasone, $400 \mu \mathrm{g}$ daily. At the time of entry all had required at least two courses of prednisolone in increased dosage for exacerbations of asthma in the preceding 12 months but not in the last four weeks.

Initially a short term double blind crossover study was performed on 20 patients. The treatment regimens were identical with those used in the long term study described below, except that each was continued for only four weeks.

The following treatment regimens were then compared in a long term study, which was also of the 
double blind crossover type: (1) prednisolone, $5 \mathrm{mg}$ (one tablet) twice daily for 24 weeks, with an intramuscular injection of saline, $2 \mathrm{ml}$, on the first day of each four week period; (2) placebo "prednisolone" tablets, one twice daily for 24 weeks, with an intramuscular injection of triamcinolone acetonide suspension (Kenalog: ER Squibb and Sons Ltd), $80 \mathrm{mg}$ on the first day of each four week period.

Each treatment regimen was continued for 24 weeks, the order being decided by random allocation but with equal numbers of patients started on each treatment. No "washout" period was included because of the severity of asthma in the patients included in the study, but some observations were limited to the later parts of each treatment period to allow for possible carry over effects.

Clinical assessments were made on entry and every four weeks thereafter. At each visit FEV ${ }_{1}$ and forced vital capacity (FVC) before and after administration of salbutamol by IPPB, body weight, blood pressure, and concentrations of urea, electrolytes, and plasma cortisol were measured. A short tetracosactrin test $(250 \mu \mathrm{g}$ given by intramuscular injection) was performed at entry and at $12,24,36$, and 48 weeks. Patients' faces were photographed at 0,24 , and 48 weeks to assess the degree of Cushingoid appearance.

If an exacerbation of asthma severe enough to warrant an increased dose of prednisolone occurred, patients were asked to stop the trial tablets and take $20 \mathrm{mg}$ of prednisolone daily for seven days. The number of times this happened was recorded, together with any side effects attributed to treatment. Patients were withdrawn from the trial if their symptoms were uncontrolled or if they developed intolerable side effects.

Patients continued on treatment with beclomethasone dipropionate, $100 \mu \mathrm{g}$ four times daily, throughout the study. Inhaled bronchodilator treatment was also continued, but oral $\beta$ agonists and theophylline preparations were not given.

Results were analysed with Student's $t$ test for paired comparisons. For body weight, systolic and diastolic blood pressure, potassium, urea, and cortisol, values obtained at the end of each period were compared with each other and with pretrial values.

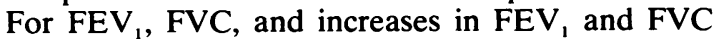
after the administration of salbutamol by IPPB, the mean results for the last eight and 16 weeks of each treatment period were compared. Single pretrial values are included in table 2 but these were not used in the analysis. Results were not compared over the whole 24 weeks of each treatment period since they might have been influenced by a carry over effect. For the same reason, the number of courses of prednisolone required for acute episodes of asthma was compared only over the last eight and 16 weeks of each treatment period.

\section{Results}

The results of the short term study are shown in table 1. No significant differences between the treatment periods were found for FEV 1 or FVC (before and after salbutamol), but at all times the values were significantly better than pretrial values. The basal plasma cortisol concentrations did not change but the tetracosactrin response after prednisolone was lower than the pretrial response $(p<$ $0.001)$ and lower than the response after triamcinolone $(p<0.01)$.

In the long term study two patients failed to complete the full period of assessment. One was withdrawn 16 weeks after the start of the first treatment period (with triamcinolone) because of gradually increasing symptoms culminating in a severe attack of asthma that required treatment in hospital for three weeks. The other was withdrawn because of the development of severe asthmatic symptoms 22 weeks after the start of the second treatment period (with prednisolone). Results from all the 18 patients who completed 48 weeks of assessment were included in the analysis.

The results are shown in tables 2-4. Mean values for $F E V_{1}$ after the last 16 and the last eight weeks were significantly higher during treatment with triamcinolone than with prednisolone $(p<0.05$ and $\mathrm{p}<0.02$ respectively). The mean values for FVC over the last 16 weeks were similarly higher during treatment with triamcinolone $(p<0.01)$, but there were no significant differences between the treatments for the mean increases in $\mathrm{FEV}_{1}$ or FVC after the administration of salbutamol by IPPB. Patients required fewer courses of prednisolone during triamcinolone treatment periods, but this difference did not reach significance.

Plasma urea concentrations were lower after treatment with triamcinolone $(p<0.001$ when compared with the pretrial values, $p<0.01$ when compared with the values after treatment with prednisolone); but the differences did not appear to be of clinical importance. The mean body weight at the end of the triamcinolone treatment period was significantly lower than that after treatment with prednisolone $(p<0.001)$. The mean morning basal plasma cortisol concentration was not significantly different after the two treatments, nor in either case did it differ from the very low pretrial value $(0.08$ (SD 0.11) $\mu \mathrm{mol} / \mathrm{l}$ ). Table 4 shows the mean increase in cortisol after a short tetracosactrin test. The increases after 12 and 24 weeks of triamcinolone 
Table 1 Results of short term study on 20 patients (mean values with standard deviations in parentheses)

\begin{tabular}{|c|c|c|c|c|c|c|}
\hline \multirow[t]{2}{*}{ Measurement } & \multirow[t]{2}{*}{ Before trial } & \multicolumn{2}{|c|}{ Prednisolone treatment } & \multicolumn{2}{|c|}{ Triamcinolone treatment } & \multirow{2}{*}{$\begin{array}{l}\text { Prednisolone } v \\
\text { triamcinolone: } \\
2 \text { and } 4 \text { week } \\
\text { comparisons }\end{array}$} \\
\hline & & After 2 weeks & After 4 weeks & After 2 weeks & After 4 weeks & \\
\hline \multirow{2}{*}{$\begin{array}{l}\text { Weight (kg) } \\
\text { Blood pressure (mm Hg) } \\
\text { systolic } \\
\text { diastolic } \\
\text { FEV (1) } \\
\text { FVC'(l) } \\
\text { FEV after }\end{array}$} & $76 \cdot 8(16 \cdot 5)$ & $76 \cdot 7(16 \cdot 6)$ & $76 \cdot 5(16 \cdot 2)$ & $76 \cdot 5(16 \cdot 5)$ & $76 \cdot 3(16 \cdot 2)$ & NS \\
\hline & $\begin{aligned} 140(22) \\
84(12) \\
1.44(0.34) \\
2.33(0.64)\end{aligned}$ & $\begin{aligned} & 134(12) \\
& 84(9) \\
& 1.81(0.48) \\
& 2 \cdot 64(0.74)\end{aligned}$ & $\begin{array}{r}133(13) \\
83(9) \\
1.78(0.45) \\
2.73(0.65)\end{array}$ & $\begin{aligned} 135(20) \\
84(12) \\
1.80(0.56) \\
2.64(0.71)\end{aligned}$ & $\begin{array}{l}135(14) \\
86(9) \\
1.81(0.56) \\
2.60(0.64)\end{array}$ & $\begin{array}{l}\text { NS } \\
\text { NS } \\
\text { NS* } \\
\text { NS* }\end{array}$ \\
\hline $\begin{array}{l}\text { salbutamol (l) } \\
\text { FVC after }\end{array}$ & $1.95(0.43)$ & $2.31(0.57)$ & $2.24(0.48)$ & $2.33(0.57)$ & $2.26(0.61)$ & NS* $^{*}$ \\
\hline $\begin{array}{l}\text { salbutamol (l) } \\
\text { Plasma urea }\end{array}$ & $2.92(0.66)$ & $3.22(0.61)$ & $3.24(0.56)$ & $3.25(0.69)$ & $3 \cdot 22(0.69)$ & NS $^{*}$ \\
\hline (mmol/l) & $5 \cdot 6(1.6)$ & $5 \cdot 5(1.5)$ & $5 \cdot 8(1 \cdot 5)$ & $5 \cdot 7(1 \cdot 5)$ & $5 \cdot 5(1.4)$ & NS \\
\hline (mmol/1) & $3.75(0.32)$ & $3.82(0.42)$ & $3.64(0.51)$ & $3.69(0.34)$ & $3.65(0.38)$ & NS \\
\hline $\begin{array}{l}(\mu \mathrm{mol} / \mathrm{l}) \\
\text { Cortisol response }\end{array}$ & $0.13(0.15)$ & $0.09(0.17)$ & $0.11(0.21)$ & $0.14(0.17)$ & $0.14(0.16)$ & NS \\
\hline$(\mu \mathrm{mol} / \mathrm{l})$ & $0 \cdot 16(0 \cdot 14)$ & & $0.05(0.07)$ & & $0.21(0.19)$ & $p=0.01^{* *}$ \\
\hline
\end{tabular}

*No significant difference between treatment periods, but at all times values were significantly higher than before treatment ( $p<0.05$ or $p$ $<0.005)$

** Pretrial $\mathrm{v}$ prednisolone period: $\mathrm{p}<0.001$; pretrial $\mathrm{v}$ triamcinolone period: NS.

Conversion: SI to traditional units-Urea: $1 \mathrm{mmol} / /=6.024 \mathrm{mg} / 100 \mathrm{ml}$; potassium: $1 \mathrm{mmol} / \mathrm{l}=1 \mathrm{mEq} / \mathrm{l} ;$ cortisol: $1 \mu \mathrm{mol} / \mathrm{l} \approx 36.23 \mu \mathrm{g} / 100$ $\mathrm{ml}$.

FVC-forced vital capacity; NS—not significant.

Table 2 Results of long term study on 18 patients (mean values for last 16 and last eight weeks of a 24 week period of treatment with standard deviations in parentheses)

\begin{tabular}{|c|c|c|c|c|c|c|c|}
\hline \multirow[t]{2}{*}{ Measurement } & \multirow[t]{2}{*}{ Before trial } & \multicolumn{3}{|l|}{ Last 16 weeks } & \multicolumn{3}{|l|}{ Last 8 weeks } \\
\hline & & Prednisolone & Triamcinolone & $p$ value & Prednisolone & Triamcinolone & $p$ value \\
\hline $\begin{array}{l}\text { FEV (l) } \\
\text { FVC'(l) } \\
\text { Increase in FEV, } \\
\text { after salbutamol }\end{array}$ & $\begin{array}{l}1 \cdot 64(0 \cdot 26) \\
2 \cdot 42(0 \cdot 62)\end{array}$ & $\begin{array}{l}1.64(0.40) \\
2.44(0.60)\end{array}$ & $\begin{array}{l}1.82(0.43) \\
2.65(0.61)\end{array}$ & $\begin{array}{l}<0.05 \\
<0.01\end{array}$ & $\begin{array}{l}1.61(0.37) \\
2 \cdot 42(0.58)\end{array}$ & $\begin{array}{l}1.84(0.45) \\
2 \cdot 63(0.66)\end{array}$ & $\begin{array}{l}<0.02 \\
\text { NS }\end{array}$ \\
\hline $\begin{array}{l}\text { atter salbutamol } \\
\text { (l) } \\
\text { Increase in FVC }\end{array}$ & $0.41(0.29)$ & $0.32(0 \cdot 17)$ & $0.35(0.17)$ & NS & $0.32(0.20)$ & $0.29(0 \cdot 16)$ & NS \\
\hline $\begin{array}{l}\text { after salbutamol } \\
\text { (1) } \\
\text { Prednisolone }\end{array}$ & $0.60(0.49)$ & $0.41(0 \cdot 36)$ & $0.37(0.25)$ & NS & $0.41(0.36)$ & $0.34(0 \cdot 25)$ & NS \\
\hline \multicolumn{2}{|l|}{$\begin{array}{l}\text { Prednisolone } \\
\text { courses (total per } \\
\text { patient }\end{array}$} & $1.56(1.89)$ & $0.61(0.92)$ & NS & $0.89(1 \cdot 18)$ & $0.33(0.59)$ & NS \\
\hline
\end{tabular}

FVC-forced vital capacity; NS—not significant.

Table 3 Results of long term study on 18 patients (mean values with standard deviations in parentheses)

\begin{tabular}{|c|c|c|c|c|c|c|}
\hline \multirow[t]{2}{*}{ Measurement } & \multirow[t]{2}{*}{ Before trial $(A)$} & \multicolumn{2}{|l|}{ After 24 weeks } & \multicolumn{3}{|c|}{ Comparisons } \\
\hline & & Prednisolone (B) & Triamcinolone $(C)$ & $A \vee B$ & $A \vee C$ & $B \vee C$ \\
\hline \multirow{3}{*}{$\begin{array}{l}\text { Weight (kg) } \\
\text { Blood pressure (mm Hg) } \\
\text { systolic } \\
\text { diastolic } \\
\text { Plasma potassium (mmol/l) } \\
\text { Plasma urea (mmol/l) } \\
\text { Morning basal plasma cortisol } \\
\text { ( } \mu \text { mol/l) }\end{array}$} & $78 \cdot 8(17 \cdot 5)$ & $80 \cdot 0(18 \cdot 7)$ & $77 \cdot 6(18 \cdot 1)$ & NS & NS & $p<0.001$ \\
\hline & $\begin{array}{c}139.8(18.0) \\
87.4(9.1) \\
3.70(0.45) \\
5.99(1.29)\end{array}$ & $\begin{array}{c}141 \cdot 1(16.9) \\
87.11(10.7) \\
3.75(0.35) \\
6.08(1.66)\end{array}$ & $\begin{array}{c}140 \cdot 0(16 \cdot 6) \\
89.5(12 \cdot 2) \\
3 \cdot 65(0.32) \\
4.94(1.32)\end{array}$ & $\begin{array}{l}\text { NS } \\
\text { NS } \\
\text { NS } \\
\text { NS }\end{array}$ & $\begin{array}{l}\text { NS } \\
\text { NS } \\
\text { NS } \\
p<0.001\end{array}$ & $\begin{array}{l}\text { NS } \\
\text { NS } \\
\text { NS } \\
p<0.01\end{array}$ \\
\hline & $0.08(0.11)$ & $0.12(0.13)$ & $0.08(0.07)$ & NS & NS & NS \\
\hline
\end{tabular}

NS-not significant. 
Table 4 Response to tetracosactrin 30 minutes after dose of $250 \mu \mathrm{g}$ in 18 patients (mean values with standard deviations in parentheses)

\begin{tabular}{|c|c|c|c|c|c|c|c|}
\hline & \multirow[t]{2}{*}{ Before trial $(A)$} & \multicolumn{3}{|l|}{ After 12 weeks } & \multicolumn{3}{|l|}{ After 24 weeks } \\
\hline & & Prednisolone (B) & Triamcinolone (C) & $\begin{array}{l}\text { p value } \\
(B \vee C)\end{array}$ & Prednisolone (D) & Triamcinolone (E) & $\begin{array}{l}\text { pvalue } \\
(D \vee E)\end{array}$ \\
\hline $\begin{array}{l}\text { Increase in plasm } \\
\text { cortisol after } \\
\text { tetracosactrin } \\
(\mu \mathrm{mol} / \mathrm{l})\end{array}$ & $0.17(0.13)$ & ${ }^{*} 0.10(0.11)$ & $0.18(0.12)$ & $<0.02$ & $0.14(0.13)$ & $0.22(0.14)$ & $<0.01$ \\
\hline
\end{tabular}

${ }^{*}$ Significantly less than pretrial value $(\mathrm{p}<0.05)$.

Conversion: SI to traditional values-Cortisol: $1 \mu \mathrm{mol} / \mathrm{l} \approx 36.23 \mu \mathrm{g} / 100 \mathrm{ml}$.

were greater than those after equivalent periods of prednisolone ( $p<0.02$ and $p<0.01$ respectively) and that after 12 weeks of prednisolone was significantly smaller than the pretrial increase $(p<$ $0 \cdot 05$ ). A normal response to tetracosactrin was defined as an increase in plasma cortisol concentration of $0.2 \mu \mathrm{mol} / \mathrm{l}(7.25 \mathrm{mg} / 100 \mathrm{ml})$ or more, 30 minutes after the intramuscular injection of $250 \mu \mathrm{g}$, from a baseline level of $0.3-0.7 \mu \mathrm{mol} / \mathrm{l}(10 \cdot 9-25.4$ $\mu \mathrm{g} / 100 \mathrm{ml})$ to at least $0.55 \mu \mathrm{mol} / \mathrm{l}(19.2 \mu \mathrm{g} / 100 \mathrm{ml})$. A subnormal response was recorded in every patient throughout the study, although one patient had a normal response at the time of entry.

\section{SIDE EFFECTS}

Side effects (table 5) were reported by 18 of the 20 patients during treatment with triamcinolone and by 12 during treatment with prednisolone. The most troublesome were menstrual disturbances and muscle aching and weakness. Four premenopausal women were included in the study and of these three reported menstrual side effects. Two developed amenorrhoea lasting for two and five months and resolving within four weeks of stopping treatment with triamcinolone; the third developed menorrhagia during treatment with triamcinolone. One postmenopausal patient developed vaginal bleeding after two triamcinolone injections. Uterine curettings were normal and the vaginal bleeding stopped

Table 5 Numbers of patients developing side effects during treatment with triamcinolone and prednisolone

\begin{tabular}{lll}
\hline Side effect & Triamcinolone & Prednisolone \\
\hline Muscle aching and & & \\
$\quad$ weakness & 6 & 2 \\
Rashes & 5 & 2 \\
Menstrual problems & 4 & \\
Facial hirsuitism & 4 & 1 \\
Depression & 3 & 3 \\
Oedema & 2 & 2 \\
Hypokalaemia & 2 & \\
Hypertension & 1 & 1 \\
Nausea & 1 & 3 \\
Bruising & & \\
\hline
\end{tabular}

during the first month after the change to prednisolone.

Muscle aching and weakness occurred in six patients while they were receiving triamcinolone and in two during treatment with prednisolone. One patient developed considerable weakness and wasting of the shoulder muscles. His symptoms started during treatment with prednisolone and increased during the first three months of triamcinolone, but then subsided despite continued treatment. Rashes occurred in five patients during triamcinolone treatment (two acneiform, two non-specific, one typical of psoriasis) and in two patients while they were having prednisolone (one acneiform, one nonspecific). One patient with mild hypertension required treatment for a gradually increasing diastolic blood pressure during the triamcinolone period. Glycosuria was not detected in any of the 18 patients during the study, but glucose tolerance tests were not performed.

No patient had to be withdrawn from the trial because of side effects.

\section{CUSHINGOID APPEARANCE}

The patient's photographs were shown in a double blind fashion to two experienced clinical endocrinologists, who were asked to assess the degree of Cushingoid appearance. Using a simple scoring system they were unable to recognise any consistent differences between the photographs taken after each treatment period either by direct comparison or when they were compared with photographs taken on entry to the study.

\section{Discussion}

The patients included in this study were known to have had poorly controlled asthma, often for several years, during which time they had been maintained on regular oral prednisolone and yet had often required courses of high dose treatment and hospital admission because of deterioration in their symptoms. The short term study was undertaken to see 
whether significant differences between the effects of oral prednisolone and intramuscular triamcinolone could be detected after periods of four weeks, but the results were inconclusive, It was, however, of interest that at the end of both treatment periods in the short term study FEV, and FVC before and after salbutamol were significantly higher than the pretrial values, even although one of the regimens was identical with the pretrial treatment. This suggests that some patients had not been taking the prescribed dose of prednisolone (10 $\mathrm{mg}$ daily) regularly during the pretrial period, and that an increase in "true" corticosteroid dosage during the close supervision of the study could also have accounted-at least partially-for the poorer tetracosactrin responses at the end of the treatment periods than before the trial.

In the long term study triamcinolone was shown to have a significant advantage over prednisolone in terms of FEV, and FVC, but experimentally it is known to have at most $20 \%$ more glucocorticoid activity than prednisolone, ${ }^{2}$ and $80 \mathrm{mg}$ every 28 days should be equivalent to a mean daily dose of only $3.43 \mathrm{mg}$ of prednisolone. This would seem to suggest that triamcinolone is a more potent agent in terms of clinical activity than is prednisolone (perhaps because of superior bioavailability or intrinsic pharmacological properties); but if that is the case the observation made in this study that the response to tetracosactrin was reduced to a lesser degree by triamcinolone than by prednisolone is unexpected and unexplained. The significant reduction in body weight at the end of the triamcinolone period might suggest less corticosteroid effect in respect of fluid retention and obesity, but loss of muscle mass from subclinical myopathy could have at least partly accounted for this observation.

This study confirms the view expressed by Peake et al' that intramuscular depot triamcinolone is a potentially useful alternative to prednisolone for the control of intractable chronic asthma. We would not normally recommend it in preference to prednisolone because some side effects, particularly menstrual irregularities, are often unacceptable and others, such as myopathy and osteoporosis, have not yet been fully assessed. It may, however, be of value in patients with severe chronic asthma in whom treatment with prednisolone has proved ineffective.

We would like to thank Dr CM Feek and Dr RS Gray of the deparment of endocrine and metabolic diseases, Western General Hospital, Edinburgh, for assessing the patients' photographs.

\section{References}

' Peake MD, Cayton RM, Howard P. Triamcinolone in corticosteroid-resistant asthma. Br J Dis Chest 1979; 73:39-44.

${ }^{2}$ Liddle GW. Clinical pharmacology of the antiinflammatory steroids. Clin Pharmacol Ther 1961; 2:615. 